\title{
Perceived Stress and Prenatal Distress during Pregnancy and its Related Factors Soheila Rabiepoor ${ }^{1}$, Maryam Abedi ${ }^{\text {r* }}$
}

1. Faculty of Nursing and Midwifery, Urmia University of Medical Sciences, Iran.

2. Faculty of Nursing and Midwifery, Bonab Islamic Azad University, Iran.

*Correspondence: Faculty of Nursing and Midwifery, Bonab Islamic Azad University, Iran.

Tel: +98-9904818352. E-mail: $\underline{\text { m.abedi931@ gmail.com }}$

Received July 12, 2018; Accepted December 17, 2019

\section{Abstract}

Background: pregnancy is one of the most stressful periods a woman experiences in her life. This study was done to determine the perceived stress and prenatal distress in pregnancy and its related factors.

Methods: The is cohort study was carried out on 110 pregnant women whit gestational age of 24 to 28 weeks who referred to Reference laboratory in Miandoab city in 2016-2017. The sample was selected based on availability. The Cohen Perceived Stress Scale (PSS) and Prenatal Distress Questionnaire (PDQ) and demographical information were used. All obtained data were analyzed in SPSS- 23 using t test, Paired-t test and person test. Significant level was considered less than 0.05 .

Results: The results of study show perceived stress and prenatal distress scores in 32-36 weeks have been uptrend than 24-28 weeks. Also, there was a significant relationship between wanted pregnancy with the mean stress score in 24-28 weeks $(\mathrm{p}=0.04)$. Also, between perceived stress score in 32-36 weeks and maternal education level $(\mathrm{p}=0.045)$ and between the distress score in 24-28 weeks pregnant and the wanting the sex of the fetus by the women. $(\mathrm{p}=0.045)$

Conclusions: According to the results, stress and anxiety of pregnant women increase with approaching delivery time; caregivers should be taken into consideration by pregnant women. In addition, the results of the study show the importance of holding educational classes and raising women's' awareness of pregnancy and childbirth and having a planned pregnancy to reduce stress and distress.

Keywords: Stress, Distress, Pregnancy

10.29252/jgbfinm.17.1.67 


\section{Introduction}

Pregnancy is a critical period in women's life. Women's physical and mental health during this period has significant effects on fetal health, successful childbirth, and lactation (1). According to the definition by Lobel M, Dunkel-Schetter C. $(2,3)$, the pregnancy stress consists of stressful events or situations, perceptions and assessments of stressors and reactions to stress, such as emotional reactions (4). Distress is the cognitive response to stressors (5) indicating the hidden psychological threats among various social groups. These pressures can be higher in certain classes of society; and the pregnant women are among these groups (6).

A new approach to stress in pregnant women suggests that pregnancy-related stress is a specific type of stress which is associated with maternal fears and concerns relating to pregnancy such as concerns about fetal health, maternal physical symptoms, parenting, relationships with others, and childbirth (7). Furthermore, women's perceptions of pregnancy and childbirth pain, fear of childbirth (8), age, low educational level, and low marital satisfaction (9), low economic status, inadequate support, poor relationship with spouse, and physical violence by spouse are also closely associated with pregnancy stress and distress (10). Evidence indicates that mothers' reaction to stress and distress changes during the pregnancy (11). In studies in Sweden and England, the prevalence of stress in pregnancy was reported to be $33-37 \%$ and $5.7 \%$ respectively (12). In Finland, researches indicated that $78 \%$ of mothers had anxiety and distress about pregnancy and childbirth during pregnancy (13). Negahban and Ansari conducted a study in Rafsanjan and found that only $7 \%$ of pregnant mothers were not distressed at the pregnancy and childbirth (14).

Stress and distress during pregnancy probably increase the pregnancy complications (15). The pregnancy distress can affect fetal physiological growth and development (16). The pregnant woman's distress also affects her and causes negative perception towards birth, unnecessary fears of childbirth and motherhood or limited activity (17). Since the pregnancy and childbirth are considered as crises in women's life, it is important to pay attention to this physiological phenomenon. Identifying women with high stress during pregnancy and providing necessary education to reduce their stress can have a significant impact on improving their mental health, and thus next generation's health (18). The present study aimed to determine the perceived stress and prenatal distress in pregnancy and its related factors. 


\section{Methods}

The present prospective cohort study was conducted on pregnant women who visited the reference laboratory of Miandoab during 2016-2017. The statistical population consisted of pregnant women at 24-28 weeks. The convenience sampling was performed, and the sample size of 100 was determined based on a study by Salari et al. with a sample error of $5 \%$ and a power of $80 \%$ (19). One hundred fifteen pregnant women entered the study with a probability of $15 \%$ drop in the sample.

$$
\begin{aligned}
Z \alpha=1.96 \quad Z \beta=1.28 \quad n & =3+\left[\frac{Z \alpha+z \beta}{c}\right]^{2} \\
c & =0.5 \times \ln \left[\frac{1+r}{1-r}\right]
\end{aligned}
$$

Inclusion criteria have been set to be including gestational age of 24-28 weeks, singleton pregnancy, no underlying diseases such as cardiovascular, renal, pulmonary, autoimmune, and diabetes during and before pregnancy; and psychiatric disorders; and use of psychotropic drugs. Data were collected using a questionnaire including demographic questionnaire, fertility information, Cohen's Perceived Stress Scale (PSS), together with Prenatal Distress Questionnaire (PDQ). The demographic characteristics questionnaire included educational levels of woman and husband, their occupation, and fertility information including pregnancy and abortion history, wanted pregnancy, wanted fetal sex, and women's interest in pregnancy. Cohen's Perceived Stress Scale (PSS) was first introduced by Cohen et al. in 1983 to measure the perceived general stress over the past month (20). A 14-item version of the scale was utilized in the present study. The scale was scored on a 5-point Likert scale including never (0), almost never (1), sometimes (2), often (3), and most often (4). The items 4- 5- 6-7- 9- 10- and 13 were inversely scored(2021). The minimum score was zero and the maximum was 56; and the higher score indicates the more perceived stress. In a study by Ghorbani et al., Cronbach's alpha was 0.81 in the Iranian society (22). The reliability of the Persian version was measured using the internal consistency; and the Cronbach's alpha coefficient was obtained equal to 0.74 (23). Prenatal Distress Questionnaire (PDQ) was designed by Alderdice and Lynn (8) with 3 subscales; distress at birth 
and infant, weight and body image, and emotions and relationships that are used to measure special distress during the pregnancy. The questionnaire has 4 questions with its items scored on a 5-point Likert scale (never, almost never, sometimes, often, and most often); the score of 0 to 48 can be obtained. The high score indicates the high level of distress in a pregnant women. Yousefi used the reliability coefficient measurement method (test-retest) and internal consistency of test (Cronbach's alpha) to assess the reliability of questionnaire. The test-retest coefficient of the whole questionnaire was 0.74 , and total internal consistency of the questionnaire was 0.78 , respectively, also PDQ showed that a good concurrent validity and internal consistency (24).

The researcher visited the health network reference laboratory where the data collected It was carried out by giving the Cohen's Perceived Stress Scale (PSS) and Prenatal Distress Questionnaire (PDQ) to the participants after providing explanations about goals and project method, for which an informed consent complying with ethical principles of the questionnaire was obtained. The questionnaire was completed by 115 pregnant women at 24-28 weeks were referred to the laboratory for routine pregnancy tests from different regions of the city. Subsequently, follow-up of women was performed at 32-36 weeks of pregnancy at healthcare centers where they were provided with healthcare services. The Cohen's Perceived Stress Scale (PSS) and Prenatal Distress Questionnaire (PDQ) were re-completed by 110 women at 32-36 weeks. Data were analyzed in SPSS-23 using T-test, paired t-test, Pearson test, and analysis of variance.

\section{Results}

According to the findings, the majority of women $(61.3 \%)$ had primary school education and $3.6 \%$ had an outdoor career. $60.4 \%$ of spouses had school primary education and only $8.2 \%$ were unemployed. $18 \%$ of women had a history of abortion and $31.8 \%$ had the first pregnancy. $68.2 \%$ of women was the second pregnancy or more. While $88.2 \%$ of women had wanted pregnancies and $91.8 \%$ expressed their satisfaction with their pregnancies, $85.5 \%$ of women sought to know their fetus's gender (Table 1). 
Table 1. Demographic characteristics and reproductive information of pregnant women

\begin{tabular}{|c|c|c|c|}
\hline \multicolumn{2}{|c|}{ Demographic characteristics } & $\mathbf{N}$ & $\%$ \\
\hline \multirow[t]{3}{*}{ Women's education } & Primary school & 68 & 61.3 \\
\hline & High school diploma & 27 & 24.3 \\
\hline & Academic & 15 & 13.6 \\
\hline \multirow[t]{2}{*}{ Women's job } & Housewife & 106 & 96.4 \\
\hline & Employed & 4 & 3.6 \\
\hline \multirow[t]{3}{*}{ Husband's education } & Primary school & 67 & 60.40 \\
\hline & High school & 30 & 27 \\
\hline & Academic & 13 & 11.8 \\
\hline \multirow[t]{2}{*}{ Husband's job } & Unemployed & 9 & 8.2 \\
\hline & Employed & 101 & 91.8 \\
\hline \multirow[t]{2}{*}{ History of abortion } & No & 92 & 83.6 \\
\hline & Yes & 18 & 16.2 \\
\hline \multirow[t]{2}{*}{ History of pregnancy } & 1 & 35 & 31.8 \\
\hline & $2 \geq$ & 75 & 68.2 \\
\hline \multirow[t]{2}{*}{ Wanted pregnancy } & Yes & 97 & 88.2 \\
\hline & No & 13 & 11.8 \\
\hline \multirow[t]{2}{*}{ Fetus sex } & Male & 65 & 59.1 \\
\hline & Female & 45 & 40.9 \\
\hline \multirow[t]{2}{*}{ Interest in pregnancy } & Yes & 101 & 91.8 \\
\hline & No & 9 & 8.2 \\
\hline \multirow[t]{2}{*}{ Choosing baby's gender } & Yes & 94 & 85.5 \\
\hline & No & 16 & 14.5 \\
\hline
\end{tabular}

According to research findings, the mean score of perceived stress and distress increased in weeks 32-36 of pregnancy compared to weeks 24-28 of pregnancy. Furthermore, distress scores also increased in weeks 32-36 of pregnancy in three fields of distress at body weight and image, distress about relationships and emotions, as well as distress at birth and fetus compared to weeks 24-28. According to paired t-test, increase in score of women's distress in weeks 32-36 was significant compared to weeks $24-28$ of pregnancy $(\mathrm{p}=0.001)$, and increase in perceived stress score in weeks 32-36 of pregnancy was insignificant compared to weeks 24-28 ( $\mathrm{p}=0.351)$. 
(Table 2)

According to the Pearson test, there was no significant relationship between mean scores of perceived stress and maternal distress scores in weeks 24-28 (P=0.877, $\mathrm{r}=0.015)$ and 32-36 $(\mathrm{P}=$ $0.990, \mathrm{r}=0.015)$.

Table 2. Comparison of mean scores of perceived stress and distress in weeks 24-28 and 3236 of pregnancy in women

\begin{tabular}{|l|c|c|c|}
\hline & Weeks 24-28 & Weeks 32-36 & P-value \\
\hline Dimensions of pregnancy distress & $25.27 \pm 4.56$ & $25.66 \pm 4.62$ & 0.351 \\
\hline Distress score of physical weight and image & $8.58 \pm 1.93$ & $9.26 \pm 1.61$ & \multirow{2}{*}{} \\
\cline { 1 - 3 } Distress score of emotions and relations & $11.09 \pm 2.19$ & $12.29 \pm 2.22$ & \\
\cline { 1 - 3 } Distress score of birth and fetus & $15.93 \pm 2.91$ & $18.46 \pm 2.54$ & \\
\cline { 1 - 3 } Pregnancy distress & $35.6 \pm 4.76$ & $40.01 \pm 4.93$ & \multirow{2}{*}{$<0.001^{*}$} \\
\hline
\end{tabular}

* Paired t-test, significance level: $\mathrm{p}<0.05$

According to Table 3, in the field of relationship between demographic characteristics and perceived stress score, there were significant relationships between maternal education levels in weeks 32-36 of pregnancy and perceived stress score $(\mathrm{p}=0.045)$ and also between wanted pregnancy and perceived stress score $(\mathrm{p}=0.04)$ in weeks $24-28$ of pregnancy. Furthermore, the stress score in weeks 32-36 had a significant relationship with wanted fetus sex by women's $(\mathrm{p}=0.025)$. In general, women's who were not willing to know their fetus's gender, had higher stress scores at the end of pregnancy.

Table 3. Assessment of relationship of demographic characteristics and mean stress scores in weeks 24-28 and 32-36 of pregnancy in women

\begin{tabular}{|l|l|l|l|l|l|}
\hline \multicolumn{2}{|c|}{ Variable } & \multicolumn{3}{c|}{ Perceived stress } \\
\cline { 2 - 4 } & weeks 24-28 & \multicolumn{1}{c|}{ P-value } & weeks 32-36 & \multirow{2}{*}{ P-value } \\
\hline \multirow{2}{*}{$\begin{array}{l}\text { wevel } \\
\text { leven's education }\end{array}$} & Primary school & $35.14 \pm 4.58$ & 0.772 & $25.33 \pm 4.65$ & $0.045^{*}$ \\
\cline { 2 - 3 } & $\begin{array}{l}\text { High school diplo- } \\
\text { ma }\end{array}$ & $25.18 \pm 4$ & & $25.17 \pm 4.14$ & \\
\cline { 2 - 3 } & Academic & $26.06 \pm 4.46$ & & $28.4 \pm 3.43$ & \\
\hline \multirow{2}{*}{ women's job } & Housewife & $25.20 \pm 4.59$ & 0.443 & $25.57 \pm 4.69$ & 0.305 \\
\cline { 2 - 3 } & Employed & $27 \pm 3.65$ & & $28 \pm 0.81$ & \\
\hline Husband's educa- & Primary school & $24.16 \pm 4.57$ & 0.825 & $25.22 \pm 4.65$ & 0.452 \\
\hline
\end{tabular}




\begin{tabular}{|c|c|c|c|c|c|}
\hline \multirow[t]{2}{*}{ tion } & High school & $25.16 \pm 4.01$ & & $25.92 \pm 4.34$ & \\
\hline & Academic & $24.61 \pm 4.55$ & & $25.92 \pm 4.34$ & \\
\hline \multirow[t]{2}{*}{ Husband's job } & Unemployed & $24.62 \pm 3.33$ & \multirow[t]{2}{*}{0.607} & $25.12 \pm 5.13$ & \multirow[t]{2}{*}{0.882} \\
\hline & Employed & $25.50 \pm 4.68$ & & $24.88 \pm 4.39$ & \\
\hline \multirow{2}{*}{$\begin{array}{l}\text { History of abor- } \\
\text { tion }\end{array}$} & No & $24.83 \pm 4.23$ & \multirow[t]{2}{*}{0.983} & $25.58 \pm 4.55$ & \multirow[t]{2}{*}{0.610} \\
\hline & Yes & $25.36 \pm 4.63$ & & $26.05 \pm 5.09$ & \\
\hline \multirow{2}{*}{$\begin{array}{l}\text { History of preg- } \\
\text { nancy }\end{array}$} & 1 & $25.26 \pm 4.93$ & \multirow[t]{2}{*}{0.942} & $25.40 \pm 4.61$ & \multirow[t]{2}{*}{0.405} \\
\hline & $2 \geq$ & $25.22 \pm 3.71$ & & $26.20 \pm 4.46$ & \\
\hline \multirow[t]{2}{*}{ Wanted pregnancy } & Yes & $24.94 \pm 4.58$ & \multirow[t]{2}{*}{$0.04 * *$} & $25.44 \pm 4.54$ & \multirow[t]{2}{*}{0.119} \\
\hline & No & $27.69 \pm 3.63$ & & $27.53 \pm 5.01$ & \\
\hline \multirow[t]{2}{*}{ Fetus sex } & Male & $24.94 \pm 5.23$ & \multirow[t]{2}{*}{0.080} & $25.13 \pm 4.85$ & \multirow[t]{2}{*}{0.153} \\
\hline & Female & $26.20 \pm 3.15$ & & $26.43 \pm 4.21$ & \\
\hline \multirow{2}{*}{$\begin{array}{l}\text { Interest in preg- } \\
\text { nancy }\end{array}$} & Yes & $25.30 \pm 4.60$ & \multirow[t]{2}{*}{0.851} & $25.55 \pm 4.70$ & \multirow[t]{2}{*}{0.401} \\
\hline & No & $25.00 \pm 3.08$ & & $26.88 \pm 3.58$ & \\
\hline \multirow{2}{*}{$\begin{array}{l}\text { Choosing baby's } \\
\text { gender }\end{array}$} & Yes & $25.22 \pm 4.79$ & \multirow[t]{2}{*}{0.765} & $25.26 \pm 4.54$ & \multirow[t]{2}{*}{$0.025^{* *}$} \\
\hline & No & $25.6 \pm 2.69$ & & $28.13 \pm 4.43$ & \\
\hline
\end{tabular}

* One-way analysis of variance, $* *$ T-test $\quad$ Significance level: $\mathrm{p}<0.05$

The women's distress scores had a relationship with wanted fetus sex in weeks 24-28 of pregnancy $(\mathrm{p}=0.045)$, and women's who were not interested in determining their fetus's sex, experienced much distress in the second trimester of pregnancy (Table 4).

Table 4. Relationship between demographic characteristics and mean scores of pregnancy distress in weeks 24-28 and 32-36 of pregnancy in women

\begin{tabular}{|c|c|c|c|c|c|}
\hline \multicolumn{2}{|c|}{ Variable } & \multicolumn{4}{|c|}{ Distress score } \\
\hline & & weeks 24-28 & P-value & weeks 32-36 & P-value \\
\hline \multirow{3}{*}{$\begin{array}{l}\text { women's education } \\
\text { level }\end{array}$} & Primary school & $35.32 \pm 4.69$ & \multirow[t]{3}{*}{0.557} & $39.85 \pm 4.19$ & \multirow[t]{3}{*}{0.825} \\
\hline & High school & $35.66 \pm 4.4$ & & $40.03 \pm 4.14$ & \\
\hline & Academic & $36.80 \pm 5.19$ & & $40.73 \pm 5.16$ & \\
\hline \multirow[t]{2}{*}{ women's job } & Housewife & $35.60 \pm 4.83$ & \multirow[t]{2}{*}{0.952} & $40.03 \pm 4.95$ & \multirow[t]{2}{*}{0.832} \\
\hline & Employed & $35.75 \pm 2.21$ & & $39.5 \pm 4.79$ & \\
\hline
\end{tabular}




\begin{tabular}{|c|c|c|c|c|c|}
\hline \multirow[t]{3}{*}{ Husband's education } & Primary school & $35.25 \pm 4.81$ & \multirow[t]{3}{*}{0.603} & $39.36 \pm 5.08$ & \multirow[t]{3}{*}{0.163} \\
\hline & High school & $36.03 \pm 4.45$ & & $36.85 \pm 4.78$ & \\
\hline & Academic & $36.46 \pm 4.46$ & & $42.38 \pm 2.63$ & \\
\hline \multirow[t]{2}{*}{ Husband's job } & Unemployed & $36.11 \pm 4.04$ & \multirow[t]{2}{*}{0.687} & $42.23 \pm 4.97$ & \multirow[t]{2}{*}{0.161} \\
\hline & Employed & $35.42 \pm 4.92$ & & $39.96 \pm 4.78$ & \\
\hline \multirow[t]{2}{*}{ History of abortion } & No & $35.54 \pm 4.38$ & \multirow[t]{2}{*}{0.746} & $39.93 \pm 4.92$ & \multirow[t]{2}{*}{0.690} \\
\hline & Yes & $35.94 \pm 6.53$ & & $40.44 \pm 5.10$ & \\
\hline \multirow[t]{2}{*}{ History of pregnancy } & 1 & $35.68 \pm 4.87$ & \multirow[t]{2}{*}{0.909} & $41.20 \pm 5.32$ & \multirow[t]{2}{*}{0.086} \\
\hline & $2 \geq$ & $35.57 \pm 4.88$ & & $39.46 \pm 4.67$ & \\
\hline \multirow[t]{2}{*}{ Wanted pregnancy } & Yes & $35.45 \pm 4.79$ & \multirow[t]{2}{*}{0.352} & $40.11 \pm 4.85$ & \multirow[t]{2}{*}{0.583} \\
\hline & No & $36.76 \pm 4.53$ & & $39.30 \pm 5.64$ & \\
\hline \multirow[t]{2}{*}{ Fetus sex } & Male & $35.33 \pm 4.40$ & \multirow[t]{2}{*}{0.477} & $40.33 \pm 4.67$ & \multirow[t]{2}{*}{0.416} \\
\hline & Female & $36 \pm 5.24$ & & $39.55 \pm 5.30$ & \\
\hline \multirow[t]{2}{*}{ Interest in pregnancy } & Yes & $35.48 \pm 4.86$ & \multirow[t]{2}{*}{0.363} & $40.06 \pm 4.91$ & \multirow[t]{2}{*}{0.718} \\
\hline & No & $37 \pm 3.27$ & & $39.44 \pm 5.34$ & \\
\hline \multirow{2}{*}{$\begin{array}{ll}\text { Choosing } & \text { baby's } \\
\text { gender }\end{array}$} & Yes & $35.24 \pm 4.80$ & \multirow[t]{2}{*}{$0.045 * *$} & $40.02 \pm 4.91$ & \multirow[t]{2}{*}{0.987} \\
\hline & No & $37.81 \pm 3.98$ & & $40 \pm 5.18$ & \\
\hline
\end{tabular}

** T-test Significance level: $\mathrm{p}<0.05$

\section{Discussion}

Pregnancy is a critical period in women's lives, providing the basis for stress, distress and depression, and is considered as the most common mental disorder during pregnancy $(25,26)$.

Findings of the present study indicated that the perceived stress by women in weeks 32-36 of pregnancy was higher than weeks 24-28 of pregnancy. The finding of Wadhwa's study indicated that women's reaction to stress changed during pregnancy; and events experienced during the early pregnancy might be more stressful than similar experiences occurring at the end of pregnancy (27). Furthermore, Correia argues that pregnancy was a stressful period of the woman's life and its severity was higher in the third trimester (28). Barjasteh et al. found in a study that as the pregnancy age increased, the rates of stress and distress experienced by women also increased (29). Furthermore, Sadeghi et al. found that stress and distress levels in the third trimester were probably higher due to approaching the delivery time (30); their results were consistent with our findings.

The pregnancy distress was also higher in weeks 32-36 than weeks 24-28. In the field of woman's characteristics during this period, Cite believes that woman begins to talk to her fetus and is concerned about the growth and development of her fetus in this period, and as the end of 
this period approaches, fear and distress multiply, and finally the maternal distress increases in the third trimester of pregnancy that is called the women's identity crisis (31). Furthermore, Azizi enumerated the sociocultural environmental conditions and mothers' unfamiliarity with pregnancy physiology, childbirth, and other subsequent issues such as infant care as the causes of increasing the mothers' distress in the third trimester of pregnancy. These problems are especially evident in the third trimester of pregnancy due to the proximity to delivery time (30).

Among different dimensions of distress, the highest level of distress is related to birth and infant, which increased in weeks 32-36 compared to weeks 24-28, which is in line with the findings of Yousefi's study (24). In fact, as the delivery time approaches, women become more anxious and distressed about the delivery and childbirth, type of delivery, pain and problems of delivery, maternal responsibility and method of caring the infant (32). In many studies, the fear of childbirth and labor pain is enumerated as the main causes of pregnant women's distress. For instance, Negahban and Ansari mentioned the fear of pain and damage to fetus as the reason for distress during the pregnancy (14). Furthermore, Borghei et al. conducted a qualitative study in 2016 and investigated the pregnant women's concerns. They found that the fetus health was the most important maternal concern during pregnancy (33). The finding of study showed that the problems of pregnancy, childbirth and hospitalization were the causes of mothers' concern. (34) According to the findings of present study, there was a significant negative relationship between mother's education and perceived stress score in weeks 32-36 of pregnancy. Firouzbakht et al. reported that more educated women were more likely to participate in pregnancy-related educational processes leading to lower stress and distress in them due to acquiring more information (35). Tanhaye et al. argued that increasing mothers' educational level could be a source of avoidance of unscientific beliefs about pregnancy in a way that knowledgeable women faced challenges and reduced their stress (36). Findings of the study were consistent with the study by Dunkel Schetter et al. (37)

Among dimensions of demographic characteristics of research units, there was a significant relationship between perceived stress and wanted pregnancy in weeks 24-28 of pregnancy $(\mathrm{P}=0.041)$. Shayeghian et al. found that the unwanted pregnancy among anxious women happens with more frequency than the non-anxious women. Their unwillingness to become pregnant had a psychological impact on their responsibility and might interfere with the child development (17). Furthermore, Mosalanezhad et al. found significant relationships between stress and 
distress with wanted and unwanted pregnancies (38). Moreover, there were significant relationships between wanted fetus sex and perceived stress score, and distress; and women who were not interested in their fetus sex, had higher disterss and stress than other women.

According to literature, there was no study on the relationship between the wanted fetus sex and maternal stress. Perhaps the women, who are interested to know their upcoming fetuses' gender, are much supported by their spouses and relatives.

\section{Conclusion}

Results of the present study indicated that the pregnant women's perceived stress and distress increased during pregnancy indicating the necessity and importance of psychiatric care during pregnancy along with physical care. In addition, the relationship between perceived stress and education level of women indicates the impact of pregnant women's knowledge on their pregnancy; hence, holding educational classes and increasing mothers' literacy levels can be effective in reducing their stress and distress. The research results also indicated that women with unintended pregnancies experienced more stress during pregnancy indicating the importance of planned pregnancies and screening for unwanted pregnancies.

It worth noting the advantages of present study that could be mentioned as the measurement of stress level and distress in two different periods in terms of gestational age. Since the sampling was done in the reference laboratory of city, the results can be generalized to all clients.

The research results targeted health professionals, midwives, and obstetricians and gynecologists; hence, health care providers and all individuals who are in contact with pregnant women are suggested to receive the necessary education about diagnosis, care, and management of stress and distress in pregnant mothers. It is also suggested to conduct further studies on psychological changes of pregnant mothers for better outcomes, as well as studies that use biochemical variables to measure stress and distress.

\section{Acknowledgements}

The present study was conducted with a code of ethics IR.UMSU.RIC.1394.205 at Urmia University of Medical Sciences. We are grateful to the respected research deputy and the honorable personnel of health centers and all pregnant mothers who cooperated in the study. 


\section{References}

1. Doyle CS. When Delivery Expectations Change: The Role Nurses Play in Reducing Parental Strees. Nursing for women's health. 2011; 15(6): 465-469. [DOI:10.1111/j.1751-
[D. 486X.2011.01680.x]

2. Lobel M, Dunkel-Schetter C. Conceptualizing stress to study effects on health: Environmental, perceptual, and emotional components. Anxiety Research. 1990; 3(3): 213-230. [DOI: $\underline{10.1080 / 08917779008248754]}$

3. Dunkel Schetter C.Psychological science on pregnancy: stress processes, biopsychosocial models, and emerging research issues. Annual review of psychology, 2011; 62: 531-558. [DOI:10.1146/annurev.psych.031809.130727]

4. Alderdice F, Lynn F, Lobel M. A review and psychometric evaluation of pregnancy-specific stress measures. Journal of Psychosomatic Obstetrics \& Gynecology. 2012; 33(2): 62-77. [DOI: 10.3109/0167482X.2012.673040]

5. Larkin KT. Stress and hypertension: Examining the relation between psychological stress and high blood pressure. Yale university press; 2008.

6. Kelly WE. Worry and sleep length revisited: Worry, sleep length, and sleep disturbance ascribed to worry. The Journal of genetic psychology.2002; 163(3): 296-304. [DOI: $\underline{10.1080 / 00221320209598685]}$

7. Alderdice F, Lynn F. Factor structure of the prenatal distress questionnaire. Midwifery. 2011; 27(4): 553-9. [DOI:10.1016/j.midw.2010.05.003]

8. Shibley Hyde J, Women's Psychology; Women's Contribution to the Human Experience, translated by: Khmaseh A. Tehran: Arjmand Publication, 2010: p. 364-65. [persian]

9. Babanazari L, Kafi M. Relationship of pregnancy anxiety to its different periods, sexual satisfaction and demographic factors. Ijpcp. 2008; 14(2): 206-213.[persian]

10. Nasreen HE, Kabir ZN, Forsell Y, Edhborg M. Prevalence and associated factors of depressive and anxiety symptoms during pregnancy: a population based study in rural Bangladesh. BMC women's health, 2011; 11(1): 22. [DOI: 10.1186/1472-6874-11-22]

11. Wadhwa PD, Entringer S, Buss C, Lu MC. The contribution of maternal stress to preterm birth: issues and considerations. Clinics in perinatology. 2011; 38(3): 351-84. [DOI:10.1016/j.clp.2011.06.007]

12. Senturk V, Abas M, Berksun O, Stewart R.Social support and antenatal depression in extended and nuclear family environments in Turkey: a cross-sectional survey. BMC psychiatry. 2011; 11(1): 48 [DOI:10.1186/1471-244X-11-48] 
13. Hanna- Leena Melender RM. Experiences of fears associated with pregnancy and childbirth: a study of 329 pregnant women. Birth, 2002; 29(2): 101-111. [DOI:10.1046/j.1523536X.2002.00170.x]

14. Negahban T, Ansari A. Does fear of childbirth predict emergency cesarean section in primiparous women? Journal of hayat. 2009; 14(4): 73-81. [persian]

15. Abedi M, Sabory E, Rabiepour S, Rasoul J. The relationship between stress in pregnancy, and pregnancy outcomes: A longitudinal study. Nursing and Midwifery Journal. 2017; 14(12): 23-45.

16. Sterlemann V, Ganea K, Liebl C, Harbich D, Alam S, Holsboer F, et al. Long-term behavioral and neuroendocrine alterations following chronic social stress in mice: implications for stressrelated disorders. Hormones and behavior. 2008; 53(2): 386-394. [DOI:10.1016/j.yhbeh.2007.11.001]

17. Z Shayeghian, S.K Rasolzadeh Tabatabaey, E Seddighi looye. Effect of Maternal Anxiety during final 3 mounths period of pregnancy on labour process and neonatal health. HAYAT. 2009; 14(4\&3): 57-64. [persian]

18. Naderyanfar F, Soleimani M, Shekhi HR. Effect of the Voice of Holy Quran on the Anxiety of Labor Candidate Pregnant Women. Quran and Medicine. 2019; 4(1): 1-4.

19. Salari P, Alavian F, Habibi Rad A, Tara F. The relationship between stress, anxiety and pain with salivary cortisol levels in first stage of labor in primiparous women. The Iranian Journal of Obstetrics. Gynecology and Infertility. 2013; 16(55): 14-21.

20. Lee EH, Review of the psychometric evidence of the perceived stress scale. Asian nursing research.2012; 6(4): 121-127. [DOI:10.1016/j.anr.2012.08.004]

21. Leung DY, Lam TH, Chan SS. Three versions of Perceived Stress Scale: validation in a sample of Chinese cardiac patients who smoke. BMC public health. 2010; 10(1): 1. [DOI: 10.1186/1471-2458-10-513]

22. Ghorbani N, Bing MN, Watson PJ, Davison HK, Mack DA.Self-reported emotional intelligence: Construct similarity and functional dissimilarity of higher-order processing in Iran and the United States. International Journal of psychology. 2002; 37(5): 297-308. [DOI: 10.1080/00207590244000098]

23. Bastani F, Rahmatnejad L, Jahdi F, Haghani H. Breastfeeding self-efficacy and perceived stress in primiparous mothers. IJN. 2008; 21(54): 9-24. [persian]

24. Yousefi R. Psychometric properties of Persian version of renatal distress questionnaire (PDQ). Nurs Midwifery J. 2015; 13(3): 215-225. [persian]

25. World Health O. Maternal mental health and child health and development in low and middle income countries: report of the meeting, Geneva, Switzerland, 30 January - 1 February, 2008. 
Geneva: World Health Organization; 2008.

26. Accortt EE, Cheadle AC, Schetter CD. Prenatal depression and adverse birth outcomes: an updated systematic review. Maternal and child health journal. 2015; 19(6): 1306-1337. [DOI: $\underline{10.1007 / \mathrm{s} 10995-014-1637-2]}$

27. Wadhwa PD, Entringer S, Buss C, Lu MC. The contribution of maternal stress to preterm birth: issues and considerations. Clinics in perinatology. 2011; 38(3): 351-384. [DOI:10.1016/j.clp.2011.06.007]

28. Correia LL, Linhares MB. Maternal anxiety in the pre-and postnatal period: a literature review. Revista latino-americana de enfermagem. 2007; 15(4): 677-683 [DOI:10.1590/S0104$\underline{11692007000400024]}$

29. Barjasteh S, Moghaddam Tabrizi F.Antenatal anxiety and pregnancy worries in association with marital and social support. The J Urmia Nurs Midwifery Fac. 2016; 14(6): 504-515.

30. Azizi S, Molaeinezhad M. Anxiety status in pregnant mothers at third trimester of pregnancy and its related factors in referrals to Bandar Abbas Hospitals in 2012. The Iranian Journal of Obstetrics, Gynecology and Infertility.2014; 17(122): 8-15.

31. Gould D. Normal labour: a concept analysis. Journal of advanced nursing. 2000; 31(2): 418427. [DOI:10.1046/j.1365-2648.2000.01281.x]

32. Howard LM, Molyneaux E, Dennis CL, Rochat T, Stein A, Milgrom J. Non-psychotic mental disorders in the perinatal period. The Lancet. 2014; 384(9956): 1775-1788. [DOI: $\underline{10.1016 / S 0140-6736(14) 61276-9]}$

33. Borghei NS, Taghipour A, Latifnejad Roudsari R. The concern of fetal health: women's experiences of worries during pregnancy. JOGI. 2016; 19(28): 10-21. [persian]

34. Meades R, Ayers S. Anxiety measures validated in perinatal populations: a systematic review. Journal of affective disorders.2011; 133(1): 1-15. [DOI:10.1016/j.jad.2010.10.009]

35. Firouzbakht M, Nikpour M, Khefri S, Jamali B, Kazeminavaee F, Didehdar M. The effectiveness of prenatal intervention on pain and anxiety during the process of childbirth-Northern Iran: clinical trial study. Annals of medical and health sciences research. 2015; 5(5): 348-352. [DOI:10.4103/2141-9248.165260]

36. Tanhae Reshvanloo F, Tavasoli Z, Talepasand S. The role of mothers'awareness about infants care in stress and anxietyduring pregnancy: An invariance based on educational level. Zanko Journal of Medical Sciences. 2018; 18(59): 80-91.[persian]

37. Dunkel Schetter C, Niles AN, Guardino CM, Khaled M, Kramer MS. Demographic, medical, and psychosocial predictors of pregnancy anxiety. Paediatric and perinatal epidemiology. 2016; 30(5): 421-429. [DOI:10.1111/ppe.12300] 
38. Kheshti A, Gholami A.The assessing mental Health in pregnancy and relative psychopathologic factor in Jahrom. Jahrom medical journal. 2007; 5(5): 22-29. [DOI: $10.29252 / \mathrm{jmj} \cdot 5 \cdot 3 \cdot 4.23$ ]

\section{Bibliographic information of this paper for citing:}

Rabiepoor S, Abedi M. Perceived Distress and Stress during Pregnancy and its Determinants in West Azerbaijan Province, 2016-2017

J Res Dev Nurs Midw, 2020; 17(1): 67-80.

Copyright $@$ 2020, Soheila Rabiepoor, Maryam Abedi. 